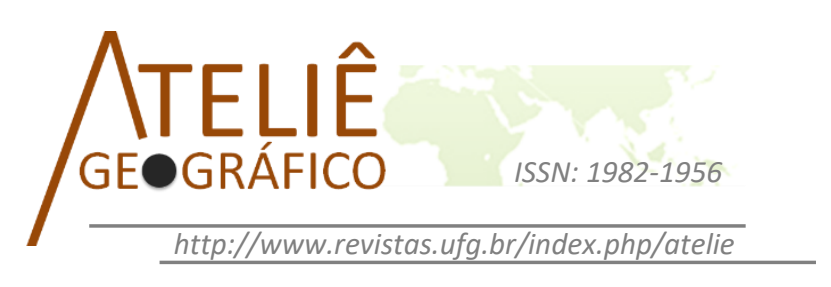

\title{
O desempenho das feiras do agronegócio no MATOPIBA: consumo produtivo para o campo moderno
}

\author{
The performance of agribusiness fairs in MATOPIBA: \\ productive consumption for the modern countryside \\ El desempeño de las ferias del agro negocio en MATOPIBA: \\ consumo productivo para el campo moderno
}

\author{
Glaycon Vinícios Antunes de Souza \\ Universidade Estadual de Campinas \\ glayconantunes@hotmail.com
}

\begin{abstract}
Resumo
No atual período de globalização, a técnica, a ciência e a informação configuram-se como tríade inseparável na realização do processo produtivo. Essa situação atinge os espaços urbanos e os espaços agrícolas. Um dos elementos que promove e dissemina novos produtos técnico-científicos para a produção agrícola moderna são as feiras/exposições agropecuárias que se conformam em verdadeiras vitrines para $o$ consumo produtivo no campo moderno. Nosso objetivo é investigar o papel desempenhado por algumas feiras do agronegócio realizadas na região agrícola atualmente conhecida como MATOPIBA (que agrega porções da Bahia, Maranhão, Piauí e do Tocantins), sobretudo a Bahia Farm Show e a Agrotins, que são as principais feiras de divulgação de inovações para o agronegócio da região.
\end{abstract}

Palavras-chave: Agricultura competitiva, Comércio, Bahia Farm Show, Agrotins.

\begin{abstract}
In the current period of globalization, technique, science and information constitute an inseparable triad in the realization of the productive process, and this situation affects urban and agricultural spaces. Some of the elements that promote and disseminate new technical-scientific products for modern agricultural production are the agricultural fairs/exhibitions, which become showcases for productive consumption in the modern countryside. The objective of this paper is to investigate the role played by some
\end{abstract}


agribusiness fairs held in the agricultural region currently known as MATOPIBA (which includes portions of Bahia, Maranhão, Piauí and Tocantins), especially Bahia Farm Show and Agrotins, which are the main fairs of innovations' propagation for agribusiness in the region.

Keywords: Competitive agriculture, Trade, Bahia Farm Show, Agrotins.

\begin{abstract}
Resumen
En el actual periodo de globalización, la técnica, la ciencia y la información están configuradas como una tríade inseparable en la realización del proceso productivo, y esa situación atinge los espacios urbanos y los espacios agrícolas. Uno de los elementos que promociona y disemina nuevos productos técnico-científicos para la producción agrícola moderna son las ferias/exposiciones agropecuarias que se hacen verdaderas vitrinas para el consumo productivo en el campo moderno. Nuestro objetivo es investigar el papel desempeñado por algunas ferias del agro negocio realizadas en la región agrícola actualmente conocida como MATOPIBA (que agrega porciones de Bahia, Maranhão, Piauí y Tocantins), sobretodo en Bahia Farm Show y Agrotins, que son las principales ferias de divulgación de innovaciones para el agro negocio de esa región.
\end{abstract}

Palabras clave: Agricultura competitiva, Comercio, Bahia Farm Show, Agrotins.

\title{
Introdução
}

Nas décadas de 1980 e 1990 observamos a expansão da agricultura moderna para os cerrados Norte e Nordeste, quando são criadas novas políticas públicas de incentivo à modernização das práticas produtivas no campo. O Programa para o Desenvolvimento do Cerrado (POLOCENTRO), executado durante o II Plano Nacional de Desenvolvimento (PND), foi um dos primeiros programas que contemplou o município de Gurupi na década de 1970, que até então fazia parte do estado de Goiás, sendo incorporado, em 1988, ao recém-criado estado do Tocantins. O programa não obteve êxito e foi desativado no início da década de 1980. Mesmo assim, esse programa teve relevância para a "[...] incorporação do Cerrado ao processo produtivo nacional e internacional, por meio da implementação de políticas de incentivos fiscais e subsídios, visando à produção de produtos para exportação, especialmente a soja" (PEIXINHO; SCOPEL, 2009, p. 98), modificando a estrutura produtiva nos Cerrados através da inserção do capitalismo na agricultura, bem como o favorecimento da acumulação de capital monopolista sobretudo no setor urbanoindustrial (INOCÊNCIO, 2010).

Segundo Inocêncio (2010), a política pública que mais obteve êxito na ocupação dos Cerrados pela agricultura moderna foi o Programa de Cooperação Nipo-Brasileira para o Desenvolvimento dos Cerrados (PRODECER). A abrangência territorial desse programa envolveu os estados de Minas Gerais, Goiás, Mato Grosso, Mato Grosso do Sul, incluindo também estados do Norte e Nordeste como Bahia, Tocantins e Maranhão. Tal programa foi criado no início de 1970, através de esforços binacionais estabelecidos pela fusão de capitais privado e público dos Estados brasileiro e japonês. O referido programa possuiu três grandes objetivos: criar novas fronteiras agrícolas nos Cerrados, aumentar a 
oferta internacional de alimentos a partir da exportação e inserir novas fronteiras agrícolas no circuito produtivo internacional do capitalismo globalizado (INOCÊNCIO, 2010).

Conforme Yoshii (2000), o PRODECER se estabelece em áreas dos Cerrados Norte e Nordeste em meados de 1980, quando foram executados os projetos de colonização Brasil Central e Ouro Verde, em Formoso do Rio Preto (BA), e em 1990, com a colonização de Gerais de Balsas e Pedro Afonso, respectivamente nos municípios de Balsas (MA) e Pedro Afonso (TO). Nos quatro projetos de colonização a área ocupada foi de 111.432 hectares (ha), sendo 31.342 ha no município de Formosa do Rio Preto (BA), 40 mil ha em Balsas (MA) e 40 mil ha em Pedro Afonso (TO), com investimentos que somam US\$ 153.327 milhões, distribuídos em 24 milhões de dólares para colonização Brasil Central e 26 milhões de dólares para Ouro Verde. Já em Pedro Afonso a quantia disponibilizada foi de US\$ 42.903 milhões, e o projeto Gerais de Balsas foi o que mais recebeu investimento, com valor de US\$ 60.424 milhões (YOSHII, 2000).

Consideramos que os investimentos realizados pelo PRODECER, foram o grande impulso modernizador na região, através da aplicação de capitais no processo produtivo, na comercialização e industrialização, bem como no incentivo à pesquisa científica com finalidade de melhorar os produtos. Os esforços de desenvolvimento de tecnologia para o campo nessas áreas foram estabelecidos por outros agentes. Conforme Bernardes (2009), a Embrapa Soja, em conjunto com a Fundação de Apoio à Pesquisa do Corredor de Exportação Norte (FAPCEN), vem desenvolvendo pesquisas em sub-regiões dos Cerrados Norte e Nordeste desde da década de 1980, fundamentalmente em Balsas (MA).

Grande parte da ação política desses programas de modernização dos Cerrados atingiu especialmente as áreas de chapadas, que eram de uso comum das populações tradicionais (camponeses, geraizeiros, tribos indígenas, etc.) para caça, colheita de frutos dos cerrados e para pecuária extensiva, foram progressivamente ocupadas por grandes propriedades agrícolas voltadas para o cultivo de monoculturas como soja, milho e em alguns casos o algodão. Nesses lugares (chapadas), a dinâmica da natureza determinava o ritmo de vida das populações tradicionais, porém essa situação é paulatinamente substituída pela dinâmica da "agricultura científica globalizada" (SANTOS, 2001, p. 88) a partir de 1990, pois são áreas mais propícias para se desempenhar a atividade agrícola de referência planetária com alto nível de mecanização, em que a técnica passa ser elemento fundamental para a concretização das práticas agrícolas competitivas. Além da referência planetária, a agricultura científica globalizada é caracterizada por ser uma atividade que responde aos mesmos imperativos que atingem outros setores da economia e nesse sentido o dinheiro torna-se uma informação necessária para a sua realização (SANTOS, 2001).

É sobretudo nos anos 2000 que verificamos uma vertiginosa expansão do agronegócio em áreas de Cerrados do Norte e do Nordeste, especialmente no Oeste baiano, Sudoeste do Piauí, Sul do Maranhão e no Tocantins. Ao tomarmos o conjunto dos municípios que compõem a região conhecida, a partir de 2015, como MATOPIBA (acrônimo que envolve as primeiras sílabas dos estados do Maranhão, Tocantins, Piauí e 
Bahia e que corresponde a 337 municípios desses estados), observamos que a soja, principal commodity cultivada na região, teve expansão da área plantada e na quantidade produzida.

Partindo dos dados do Instituto Brasileiro de Geografia e Estatística (IBGE) sobre a Produção Agrícola Municipal (PAM) verificamos que a área plantada de soja aumentou $310 \%$ entre os anos de 2000 e 2015, e no mesmo período a quantidade produzida obteve crescimento de quase $400 \%$ (IBGE/PAM, 2017). Em dados absolutos, que podem ser observados na Tabela 1, a área plantada de soja passou de quase 905 mil ha, em 2000, para mais de 3,6 milhões ha, em 2015; números surpreendentes também são constatados com relação ao crescimento do volume produzido, para o mesmo período a produção de soja saltou de aproximadamente 2,2 milhões de toneladas (t.) para cerca de 10,7 milhões.

Tabela 01: Área plantada e quantidade produzida de soja no MATOPIBA

\begin{tabular}{|c|c|c|c|c|}
\hline \multirow{2}{*}{ Estados* } & \multicolumn{2}{|c|}{ Área plantada (ha) } & \multicolumn{2}{c|}{$\begin{array}{c}\text { Quantidade produzida } \\
\text { (toneladas) }\end{array}$} \\
\cline { 2 - 5 } & 2000 & 2015 & 2000 & 2015 \\
\hline Tocantins & 57.919 & 830.031 & 144.362 & 2.418 .367 \\
Maranhão & 178.716 & 753.880 & 454.781 & 2.075 .708 \\
\hline Piauí & 40.004 & 659.779 & 100.963 & 1.751 .219 \\
\hline Bahia & 628.356 & 1.440 .113 & 1.508 .115 & 4.513 .633 \\
\hline MATOPIBA & $\mathbf{9 0 4 . 9 9 5}$ & $\mathbf{3 . 6 8 3 . 8 0 3}$ & $\mathbf{2 . 2 0 8 . 2 2 1}$ & $\mathbf{1 0 . 7 5 8 . 9 2 7}$ \\
\hline
\end{tabular}

Fonte: IBGE/ PAM (2017).

Org.: Dados trabalhados pelo autor (2017).

Legenda: * Porções dos estados inseridos no MATOPIBA.

Perante esse crescimento produtivo agrícola, o Estado brasileiro, com base nos estudos da Empresa Brasileira de Pesquisa Agropecuária (EMBRAPA), e por intermédio do Grupo de Inteligência Territorial Estratégica (GITE), delimitou um recorte geográfico para o desenvolvimento de políticas agropecuárias na região denominada de MATOPIBA. Conforme dados do GITE (2014), o MATOPIBA é composto por 337 municípios dos quatro estados (Figura 1), englobando todos os 139 municípios do Tocantins (38\% da região ou cerca de 27,7 milhões de ha), 135 municípios das porções Sul e Leste do Maranhão (compondo cerca de $33 \%$ ou 23,9 milhões de ha do MATOPIBA), 30 municípios no Oeste baiano (aproximadamente de 18\% da região ou 13,2 milhões ha), e 33 municípios do Sudoeste do Piauí ( $11 \%$ da ou 8,2 milhões ha da região). Essa região resulta de um conjunto de informações e dados para o reconhecimento das condições agrícola, agrária, natural, socioeconômica e também da infraestrutura dessa porção do país, com o intuito de elaborar diagnósticos e relatórios que sirvam de base ao planejamento estatal para o agronegócio.

A região de MATOPIBA é oficialmente reconhecida pelo Estado como área estratégica para a expansão do agronegócio a partir da criação do Plano de Desenvolvimento Agropecuário (PDA) do MATOPIBA, criado em 2015. O PDA do 
MATOPIBA configura-se como uma ferramenta importante para a difusão e consolidação do agronegócio, pois as diretrizes que dão sustentação ao plano são voltadas para o fortalecimento de setores indispensáveis para essa atividade, tais como a melhoria das condições de logística para a circulação de grãos e o desenvolvimento de novas tecnologias de produtos para o campo moderno; por fim, busca-se o fortalecimento da classe média rural (BRASIL, 2015). Tomando como base as informações do censo agropecuário de 2006, bem como o valor do salário mínimo da época - 300 reais, o GITE (2015) reconheceu que a denominada classe média rural é representada pela população que possuía uma renda entre 10 e 200 salários mínimos. Assim, o PDA é uma ação estatal carregada de expectativas e intencionalidades para tornar MATOPIBA mais competitiva e atrativa para a atividade das grandes corporações do agronegócio.

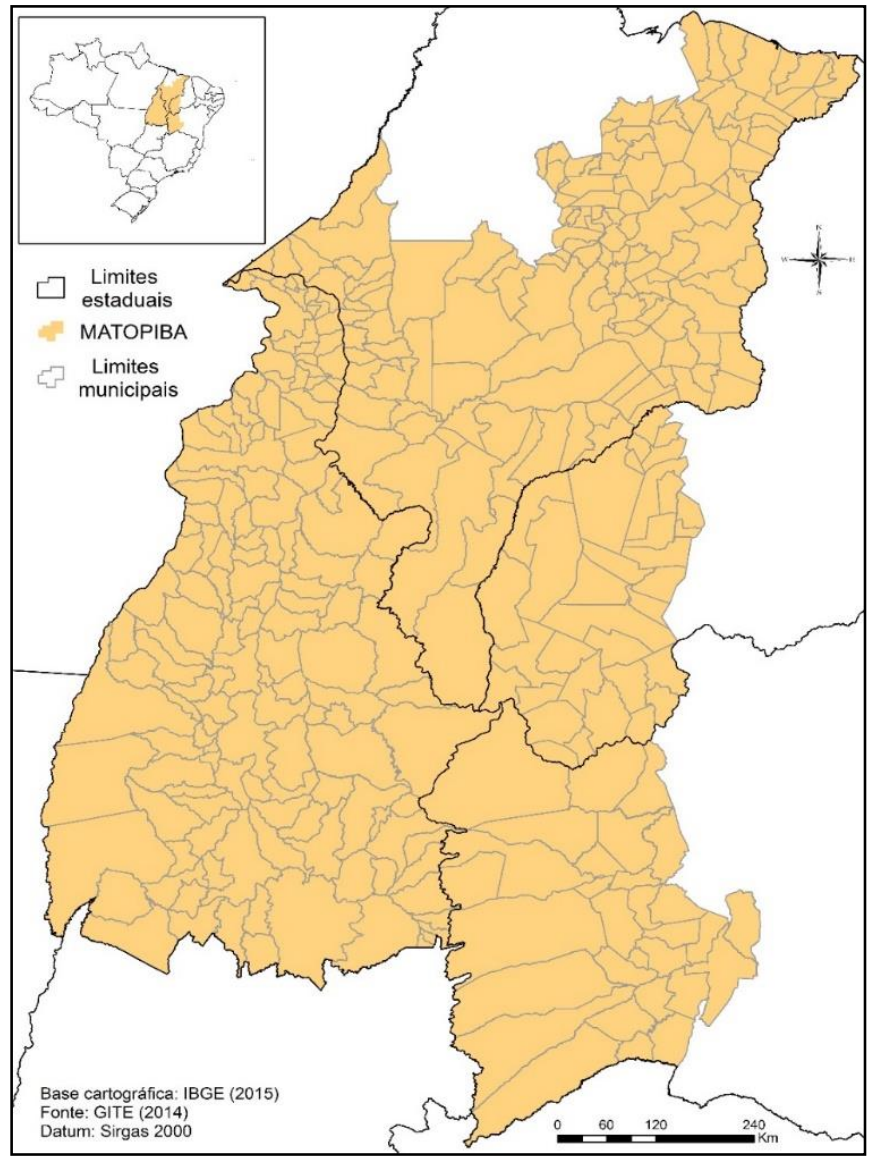

Figura 1. Recorte regional do MATOPIBA.

Fonte: Elaborado pelo autor (2018). 
De 2000 a 2015 várias empresas de grande porte, exportadoras de grãos, estendem seus nexos corporativos em diferentes pontos da região, sendo resultado e resultante do processo de expansão do agronegócio no MATOPIBA. Entre as maiores corporações que dinamizam o circuito espacial produtivo (SANTOS; SILVEIRA, 2011) da soja, destacam-se a ADM, a Multgrain, a Algar Agro, a Amaggi \& LDC, a SLC Agrícola e a CGG, além da Bunge e da Cargill. Essas empresas controlam diferentes etapas do processo produtivo, como circulação, distribuição e, em alguns casos, a industrialização dos grãos, o que conferem a esse conjunto de empresas um poderoso controle do direcionamento dos fluxos produtivos.

Ainda cabe mencionar o esforço estatal, sobretudo no Governo Lula (2003-2011), para ativar um importante sistema de engenharia para o transporte de commodities agrícolas produzidas nessa região do agronegócio, a Ferrovia Norte-Sul, pois no atual período a logística assume relevância ainda maior para a circulação corporativa (CASTILLO, 2011). A Ferrovia Norte-Sul é importante para a circulação de grãos advindos do MATOPIBA, porque esse objeto geográfico se conecta à Estrada de Ferro dos Carajás (no Maranhão) que se liga diretamente com os portos em São Luís (MA). Nesse sentido, a Ferrovia Norte-Sul configura-se como uma "ferrovia do agronegócio", devido ao seu caráter monofuncional/especializado no transporte de mercadorias volumosas e com baixo valor agregado, como a soja e o milho (VENCOVSKY, 2011, p. 98).

Diante da renovação da composição técnica e normativa no MATOPIBA, alcançada por meio da difusão do agronegócio em diferentes porções dessa região, observamos a constituição de forma seletiva e como mancha de um meio técnicocientífico-informacional (SANTOS, 2001, 2002), que colabora para o aumento da divisão social e territorial do trabalho. Esse processo proporciona a intensificação dos fluxos de informação, mercadorias, pessoas e ordens dessa região com outros lugares do país e do mundo. Nesse contexto, emerge uma agricultura competitiva no MATOPIBA, que foi respaldada a partir do uso de ferramentas embutidas de conhecimento científico e informacional, que estão presentes nos agroquímicos e nos objetos técnicos como máquinas e implementos agrícolas (tratores, arados, pulverizadores, entre outros), pivôs centrais para irrigação, aviões para disseminação de agrotóxicos, sementes geneticamente modificadas, ou seja, uma família de ferramentas modernas para o campo.

A modernização das práticas agrícolas no MATOPIBA demanda uma gama variada de serviços e produtos carregados de elemento técnico-científico, e uma das formas de suprir esse tipo de consumo acontece mediante a realização de feiras e exposições agropecuárias. Observamos o surgimento de um conjunto de feiras/exposições comerciais especializadas para atender às necessidades do agronegócio, sobretudo no que diz respeito à produtos e serviços para o desenvolvimento de uma agricultura competitiva. As feiras do agronegócio são importantes eventos para servir as demandas de consumo produtivo do campo moderno (ELIAS, 2003; SANTOS, 2009), que é compreendido como "[...] associado à produção, que não se esgota em si, mas desenvolve atividades terciárias precedentes à produção material e sem as quais ela não pode-se realizar" (ELIAS, 2003, 
p. 188). Assim sendo, o consumo produtivo é elemento indispensável para as práticas agrícolas modernas, sem a aquisição de mercadorias e serviços especializados (que são encontrados nas cidades) não observaríamos a atual configuração do agronegócio no MATOPIBA.

A realização das feiras do agronegócio é uma das variáveis que nos sinaliza a constituição de um novo período histórico no MATOPIBA, pois estas colaboram para a inserção de um novo conjunto de práticas sociais, que são perceptíveis pela renovação da composição técnica e política no território, já que são espaços de difusão de novas ferramentas (carregadas de intencionalidades e ideologias) para o desenvolvimento da produção agrícola. Dessa maneira, as feiras do agronegócio se configuram como importantes variáveis de investigação para compreender o uso do território nessa região agrícola.

O território é categoria central para o entendermos a nova configuração das atividades agrícolas no Brasil, uma vez que comporta os meios necessários para a acumulação de capital do agronegócio baseado na superexploração do trabalho e dos recursos naturais, na busca da renda fundiária, mas também na incorporação de inovação técnico no processo produtivo que visa maior produtividade. A compreensão do território usado (SANTOS; SILVEIRA, 2011) nos auxilia a desvendar a dinâmica territorial como um todo, dos fixos e dos fluxos, das normas e das técnicas, do passado e do presente, permitindo desta forma uma visão não fragmentada dos processos históricos, sociais, políticos e econômicos, do território habitado. Esse conceito busca a compreensão da totalidade do espaço, que está em constante transformação. Portanto, o território usado possui uma dimensão política que nos permite avaliar os usos corporativos das grandes empresas do agronegócio no território.

Para os atores hegemônicos o território usado é um recurso, garantia da realização de seus interesses particulares. Desse modo, o rebatimento de suas ações conduz a uma constante adaptação de seu uso, com a adição de uma materialidade funcional ao exercício das atividades exógenas ao lugar, aprofundando a divisão social e territorial do trabalho, mediante a seletividade dos investimentos econômicos que geram um uso corporativo do território. (SANTOS et al., 2000, p. 108).

As feiras do agronegócio são um dos elementos para compreendermos o uso corporativo no campo brasileiro, pois esses eventos oportunizam a racionalização do espaço agrícola ao imperativo de competitividade, uma das características do mercado globalizado. Essas feiras são verdadeiros palcos de exibicionismo e da espetacularização dos modernos objetos produzidos pelo conhecimento técnico e científico, conformando em importantes lugares de coesão de empresas especializadas na comercialização e na oferta de serviços para às demandas produtivas do campo moderno, ou seja, são eventos comerciais de difusão tecnológica para o agronegócio. 
Desse modo, temos como objetivo neste trabalho compreender o papel desempenhado pelas exposições/feiras agropecuárias realizadas no MATOPIBA. Tendo o intuito de apreender os principais tipos de produtos, serviços e as inovações tecnológicas voltadas para o agronegócio, levantando as principais empresas expositoras, a origem dessas empresas, bem como os fluxos, as trocas e a difusão do consumo produtivo promovidos por essas feiras (ELIAS, 1999), com ênfase na Agrotins (realizada em Palmas/TO) e Bahia Farm Show (realizada em Luís Eduardo Magalhães/BA), que são as maiores feiras do agronegócio dessa região.

Neste trabalho, o recorte territorial do MATOPIBA, proposto pela Embrapa, foi base para o levantamento de dados secundários, tais como a produção agrícola municipal (quantidade produzida e área plantada) e informações sobre as feiras/exposições do agronegócio (quantas existem, volume de negócios, número e origem dos expositores, público visitante, entre outros) presentes na região. Dessa forma, tivemos como principal fonte de dados sobre a área plantada e a quantidade produzida, sobretudo para a soja, o IBGE. Os relatórios sobre o balanço das feiras do agronegócio (em especial os da Agrotins), consultas nos sites das feiras - da Bahia Farm Show, Agrotins e Agrobalsas (realizada em Balsas/MA) -, reportagens jornalísticas (G1 e Agronews Oeste), secretarias estaduais da agropecuária, bem como as Federações de Agricultura e Pecuária dos estados da Bahia, Maranhão e Tocantins, foram as principais fontes de dados utilizadas para a análise.

Somando-se a essas estratégias metodológicas, sinalizamos a realização de trabalho de campo, em maio de 2016, em diferentes cidades da região (Balsas/MA, Uruçuí/PI, Bom Jesus/PI, Porto Nacional/TO, Pedro Afonso/TO e Luís Eduardo Magalhães/BA) ao qual tivemos a oportunidade de participar da Bahia Farm Show. Por fim, fizemos uma revisão teórico-metodológica sobre o tema em questão, tomando como norte as proposições de Elias $(1999,2003)$, que reconhece a importância das feiras do agronegócio como sendo uma das variáveis de análise para compreensão do uso do território no campo brasileiro.

\section{Exposições/feiras do agronegócio no MATOPIBA: difusão de tecnologias e o atendimento do consumo produtivo}

Conforme Elias (2003), o consumo apresenta-se no atual período técnicocientífico-informacional como uma ideologia que é disseminada nos objetos, já que são formas dotadas de conteúdos e intencionalidades (SANTOS, 2002), quer por sua presença e uso imediato ou pela possibilidade de obtê-las no futuro. Nesse sentido, o consumo realizado a partir dos objetos técnicos tem o poder de influenciar na organização da vida social e territorial, visto que "[...] consumo é tão contagiante que passa a representar um papel motor e perverso na sociedade atual, transitando pelo próprio aprendizado e condicionamento social" (ELIAS, 2003, p. 189). Nessa perspectiva, o consumo produz uma psicosfera - esfera dos desejos, sentimentos, ideologias, crenças - que se sustenta por 
meio de uma tecnosfera - esfera da materialidade, dos objetos, dos fixos - (SANTOS, 2002), pois "essa psicosfera produz a busca social da técnica e a adequação comportamental à interação moderna entre tecnologia e valores sociais" (RIBEIRO, 1991, p. 48).

Como sinalizado por Pereira (2011), as exposições/feiras do agronegócio são importantes lugares para a difusão de novas tecnologias para o consumo produtivo do campo moderno, mas são também eventos agrícolas que proporcionam a constituição de uma psicosfera modernizadora, que é legitimada pelos discursos da elite dirigente local (prefeitos, vereadores, deputados e governadores) e pelos meios de comunicação em que ocorrem tais feiras. Nas palavras do autor, os veículos locais de comunicação garantem "legitimidade às ações públicas e privadas que organizam a produção moderna no campo, construindo no imaginário social uma idéia de progresso e de modernização" (PEREIRA, 2011, p. 14). Portanto, essas feiras/exposições agropecuárias incentivam e legitimam a expansão do agronegócio pelo território brasileiro, incluindo o MATOPIBA, produzindo de forma dialética uma tecnosfera e uma psicosfera modernizadora.

Nos últimos anos, um conjunto de exposições/feiras agropecuárias foram realizadas no MATOPIBA. Segundo informações da Secretaria de Desenvolvimento Rural do Piauí (SDR, 2013), foram realizadas em 2013 duas feiras ou exposições agropecuárias em municípios piauienses inseridos no MATOPIBA. No ano de 2015, houve no Oeste baiano duas feiras/exposições agropecuárias (FAEB, 2015), ainda nesse ano aconteceram 14 eventos agropecuários nos municípios do Maranhão presentes na região do MATOPIBA (FAEMA/SENAR, 2015). Por fim, em 2016 ocorreram mais de 40 exposições/feiras agrícolas e pecuárias no estado do Tocantins (FAET, 2016). Cabe salientar que muitas dessas exposições possuem como importantes organizadores as Federações de Agricultura e Pecuária, nesse sentido, é possível que haja outros eventos agropecuários menores que não possuem apoio dessa instituição de classe.

Comumente as feiras do agronegócio são realizadas nos municípios em que a atividade agropecuária dinamiza a economia do lugar, e acontecem em porções do espaço mais racionalizados ao agronegócio. Estas ocorrem em municípios produtores de soja (Figura 2) que normalmente possuem grandes áreas plantadas dessa commodity, mas estão vinculadas sobretudo com as cidades que tem o terciário (serviço e comércio) especializado para atender as demandas produtivas do agronegócio. As principais feiras do agronegócio no MATOPIBA são: a Piauí Exposhow, realizada em Bom Jesus (PI), é considerada a maior do Piauí; a maior do Maranhão acontece em Balsas - Agrobalsas; no Tocantins, a maior da região Norte e a oitava maior do Brasil, é feita em Palmas - Agrotins (AGROTINS, 2016); e, por fim, no município de Luís Eduardo Magalhães (BA) realizase a Bahia Farm Show, considerada a terceira maior feira do agronegócio do país (BAHIA FARM SHOW, 2017).

Essas feiras do agronegócio estão relacionadas diretamente com a expansão da produção de soja e com ela a reestruturação urbana para atender as demandas de consumo produtivo do agronegócio. As feiras realizadas nos municípios supracidataos surgiram 
justamente no período de maior difusão do agronegócio no MATOPIBA, a partir dos anos 2000 , sinalizando que esse processo vem implicando na articulação de novos eventos para o consumo produtivo agrícola moderno.

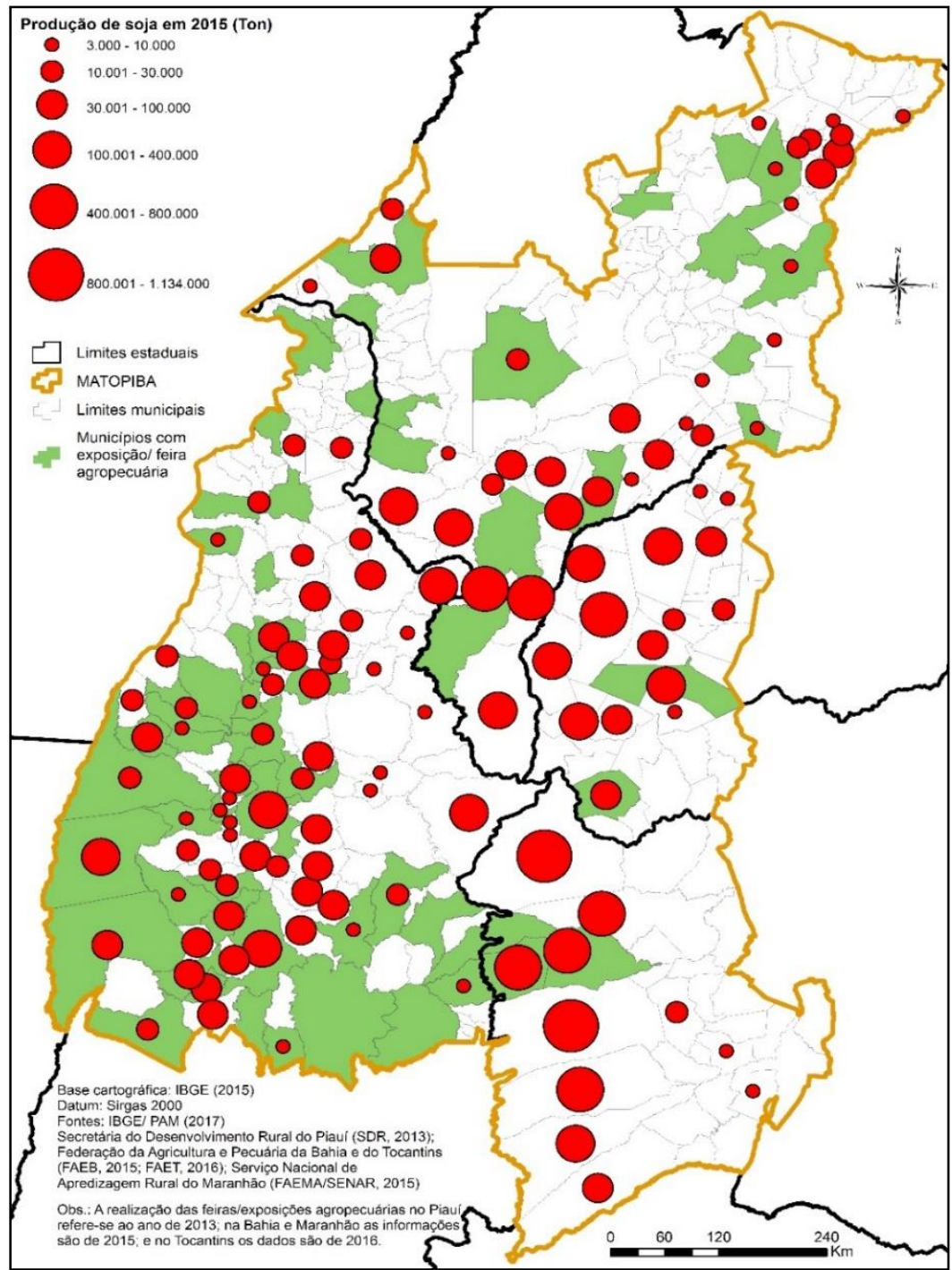

Figura 2. Feiras/exposições agropecuárias e produção de soja (a partir de 3 mil ton.) por municípios no MATOPIBA. Fonte: Elaborado pelo autor (2017).

Luís Eduardo Magalhães (BA), Balsas (MA), Bom Jesus (PI) e Palmas (TO), conjuntamente produziram um pouco mais de 1 milhão de toneladas de soja em 2015, o 
que equivaleu a aproximadamente $11 \%$ de toda soja colhida no MATOPIBA (IBGE/ PAM, 2017). É importante sinalizar que a produção de soja em Palmas é pequena se comparada aos grandes municípios produtores dessa commodity, contudo, o município em questão está inserido em uma das regiões mais dinâmicas do MATOPIBA, que é a microrregião de Porto Nacional, onde se colheu quase 476 mil toneladas de soja em 2015 (IBGE/ PAM, 2017).

Somando à questão produtiva, essas feiras acontecem em cidades mais estruturadas tecnicamente e políticamente para o melhor desempenho produtivo e lucrativo das grandes corporações. São nessas cidades que observamos a gestão da produção agrícola, bem como a presença de empresas especializadas para atender as necessidades do consumo produtivo para o campo moderno. Nas palavras de Santos (2009, p. 56), as cidades, principalmente as locais,

[...] representam estoques de meios de consumo, estoques de sementes e implementos, estoques de capital de giro (agora indispensável), estoques de mão-de-obra nos mais diversos níveis, centros de transportes e de comunicações, pólos de difusão de mensagem e ordens.

A realização das maiores feiras do agronegócio nos evidencia o nível de especialização do terciário das cidades que promovem esses eventos comerciais. Percebemos uma inter-relação entre os grandes municípios produtores de commodities agrícolas com as sedes municípiais que abrigam as condições gerais para a reprodução do agronegócio, tais como Bom Jesus, Balsas e Luís Eduardo Magalhães. Denise Elias (2006) denomina essas cidades, que possuem as condições gerais para a realização do campo moderno, como cidades do agronegócio, pois essas passam por uma reestruturação do setor terciário para atender as demanas da agricultura científica globalizada. As cidades do agronegócio são pontos indispensáveis para a realização da atividade agrícola dos municípios com maior área e quantidade produzida de soja, já que essas cidades abrigam um conjunto de comércio e serviços sem os quais o agronegócio não se realizaria, evidenciando a relação de complementariedade entre a cidade e o campo.

A Piauí Exposhow teve sua primeira edição no ano de 2008 na cidade de Bom Jesus (PI), e é fruto da iniciativa da Fundação de Defesa Ecológica do Cerrado (FUNCERRADO) com parceria da prefeitura municipal, do governo estadual, dos bancos públicos (Banco do Brasil e Banco do Nordeste) e de entidades de classes relacionadas com a agricultura moderna. Essa feira do agronegócio tem como objetivo promover a atividade agrícola competitiva nos cerrados do Sudoeste do Piauí, através da difusão de novos equipamentos agrícolas. Nela, os grandes produtores agrícolas têm a oportunidade de adquirir maquinários e implementos agrícolas a partir do financiamento realizado pelos bancos presentes nessa feira, que é realizada no Parque de Exposições Vale do Gurguéia em um espaço de 150 mil metros quadrados. Há também a oferta de palestras, fórum e debates sobre diversos temas relacionados com a atividade agrícola, e ainda são realizadas apresentações musicais durante o evento. 
Em 2012, a Piauí Exposhow reuniu cerca de 50 expositores representando 180 fábricas de máquinas agrícolas, e também estavam presentes outras firmas de comercialização de agroquímicos, sementes, entre outros (TEIXEIRA, 2013). Tinha-se a expectativa de movimentar aproximadamente R \$200 milhões na comercialização de produtos e serviços durante a feira realizada em 2012 (TEIXEIRA, 2013). Em 2014, o volume de negociação manteve-se igual aos dos anos anteriores, somando cerca de $\mathrm{R} \$ 200$ milhões, mas com uma infraestrutura maior, que contou com 70 estandes ocupados por 230 empresas (TELES, 2014; G1, 2014). Somando-se a dinamização da economia urbana de Bom Jesus, a Piauí Exposhow influencia na dinâmica regional do Sudoeste do Piauí através do deslocamento de pessoas de diversos municípios próximos da cidade que acolhe essa feira, pois em 2016 a expectativa era de que 60 mil pessoas entre expositores, produtores rurais, estudantes, e o público em geral fossem à essa feira (COSTA, 2016).

Outra importante feira do agronegócio na região é a Agrobalsas, cuja realização se dá em Balsas (MA) desde o ano 2000, tendo como finalidade estimular o comércio de novas tecnologias agrícolas (ALVES, 2005). A Agrobalsas é organizada pela Fundação de Apoio à Pesquisa do Corredor de Exportação Norte (FAPCEN), empresa privada que visa o desenvolvimento de tecnologias para tornar a produção agrícola mais produtiva. Como já sinalizado anteriormente, a FAPCEN em parceria com a Empraba Soja, vem desenvolvendo pesquisas na área de biotecnologia agrícola desde 1980, sendo disponibilizados ao mercado diversos tipos de produtos adaptados às condições de clima e solo da região. Nesse sentido, a FAPCEN é um importante agente corporativo do agronegócio no MATOPIBA, e assim podemos apreender o quanto a feira do agronegócio organizada por essa instituição é uma das mais integradas com a racionalidade da agricultura científica globalizada (SANTOS, 2001).

Segundo Alves (2005), a edição de 2003 da Agrobalsas teve cerca de 10 mil visitantes e movimentou $\mathrm{R} \$ 45$ milhões em negócios; o volume de negócios produzidos nessa feira saltou para R \$ 300 milhões na edição de 2014 (G1, 2015), demonstrando que esse evento agrícola vem se fortalecendo juntamente com as práticas do agronegócio nessa porção do MATOPIBA. Em 2016 foi realizada a 14a edição que contou com apoio do sindicato e associação de produtores agrícolas, e dos governos municipal, estadual e federal, sendo patrocinada pelos bancos do Nordestes, do Brasil, da Amazônia e pela empresa que administra o Porto de Itaqui (Empresa Maranhense de Administração Portuária - EMAP).

A Agrobalsas de 2016 aconteceu na fazenda Sol Nascente, cuja infraestrutura montada somou cerca de $2.600 \mathrm{~m}^{2}$ que foram divididos em vários espaços de exposição, sendo eles: espaço de máquinas e implementos agrícolas, espaço vitrines vivas (área de campo para demonstração de cultivos) e exposição de animais, entre outros (AGROBALSAS, 2016). Ainda em 2016 foram realizadas muitas palestras com temas diversos, tendo como exemplo: práticas de pulverização, perfil do solo, produtividade agrícola, mudanças climáticas, mercado de commodities e gestão de risco, assim por diante. Percebe-se que essas feiras do agronegócio também são espaços de divulgação de 
conhecimento, com o intuito de informar os produtores agrícolas as melhores estratégias para tornar a produção mais competitiva.

A presença de políticos é comum nas feiras do agronegócio, o que fomenta uma psicosfera (SANTOS, 2002) que estimula o uso de um conjunto de objetos técnicos (tecnosfera) considerados indispensáveis para a prática do agronegócio, e nesse sentido cria um imaginário que a agricultura competitiva só se realiza mediante o uso de tecnologia embutida com informação e ciência. As ações e discursos formulados pelos políticos, bem como agentes privados e entidades de classe agrícola, legitimam a inserção de uma racionalidade técnica e mercadológica na produção agropecuária moderna, e de certa forma incentivam o aumento do consumo produtivo dando mais credibilidade para a realização das feiras do agronegócio, visto que elas são grandes vitrines do consumo de produtos e serviços inerentes ao campo moderno.

A psicosfera modernizadora torna-se evidente nas declarações propagadas em diferentes momentos durante as feiras do agronegócio. Essa situação pode ser exemplificada durante abertura da Agrotins de 2016, quando o governador do Tocantins pronunciou: para que bons "[...] resultados sejam alcançados é preciso que cada produto seja técnica e cientificamente estudado". Nessa mesma perspectiva, o secretário de agropecuária anuncia que há “[...] a necessidade contínua de adoção de tecnologias relacionadas ao setor (agronegócio). A Agrotins cumpre um papel importante na construção e transferência de conhecimento e informação" (AGROTINS, 2016, p. 5). Portanto, é assim que observamos a relação dialética entre psicosfera e tecnosfera, pois

Ao mesmo tempo em que se instala uma tecnosfera dependente da ciência e de tecnologia, cria-se, paralelamente, e com as mesmas bases, uma psicosfera. A tecnosfera se adapta aos mandamentos da produção e do intercâmbio e, desse modo, frequentemente traduz os interesses distantes; [...] a psicosfera, reino das idéias, crenças, paixões e lugar da produção de um sentido, também faz parte desse meio ambiente, desse entorno da vida, fornecendo regras à racionalidade ou estimulando o imaginário. (SANTOS, 2002, p. 255-256).

A primeira edição do Agrotins deu-se no ano de 2001, no município de Porto Nacional. A partir da segunda edição a feira do agronegócio passou a ser realizada anualmente no município de Palmas, no Centro Agrotecnológico. Segundo informações da Agrotins (2016), na edição de 2016 foram utilizados cerca de 60 hectares do Centro Agrotecnológico para montagem de infraestrutura que incluiu pavilhões, estandes, auditórios, praça de alimentação, instalações para animais, vitrines tecnológicas, entre outros.

A Agrotins resulta de esforços do governo do Tocantins, com envolvimento de inúmeras secretarias e órgãos relacionados com o setor agrícola, contando com o apoio de instituições financeiras, do setor privado e representantes de classe (sindicatos patronais). O grande objetivo dessa feira do agronegócio é a divulgação e difusão de novas 
tecnologias para a agropecuária do estado, dando ênfase nos setores agrícola, pecuária (bovino e caprino), de flores tropicais e piscicultura. Além disso, outro grande interesse é promover a comercialização de produtos agrícolas para a realização do agronegócio. Assim, essa feira de tecnologia agropecuária visa o aprofundamento do agronegócio no Tocantins a partir da difusão de novas tecnologias para o campo proporcionando a diminuição de custos e aumento da produtividade.

O dinheiro antecipado, em forma de crédito, é elemento indispensável para ter acesso ao consumo de importantes serviços e produtos agrícolas ditos modernos, a presença de agentes financeiros é relevante para a realização das feiras do agronegócio. Em 2001 estavam presentes na Agrotins o Banco do Brasil e o Banco da Amazônia, além da Credcop. Em 2016 juntaram-se a esses bancos a Caixa Econômica Federal, o Banco Bradesco, o Banco Fábrica e Financeiros, entre outros. O volume de crédito liberado por essas instituições financeiras passou de $\mathrm{R} \$ 7$ milhões para quase $\mathrm{R} \$ 390$ milhões, entre 2001 e 2016 (AGROTINS, 2001, 2016). Segundo informações da Agrotins (2016), em 2016 cerca de $86 \%$ do volume das negociações realizadas na feira, que somou um pouco mais de R \$ 451 milhões, tiveram êxito devido a disponibilização de crédito ofertado pelas instituições financeiras presentes na Agrotins. Nesse sentido, a obtenção de financiamento agrícola é o consumo produtivo de primeira instância, que animam os fluxos e as trocas comerciais nos municípios que acolhem essas feiras do agronegócio.

A verticalização da oferta do crédito agrícola também é resultado da presença do conhecimento científico nos objetos técnicos divulgados e comercializados na Agrotins, assim constatamos uma considerável participação de instituições de pesquisa voltadas para o desenvolvimento de tecnologias para o campo. Em 2016 várias instituições de pesquisa participaram dessa feira do agronegócio, dentre elas: 12 unidades diferentes da Embrapa, as Universidades Federal e Estadual do Tocantins, Instituto Federal do Tocantins e Faculdade de Tecnologia de São Paulo (AGROTINS, 2016). A quantidade significativa de instituições de pesquisa tecnológica e biotecnológica na Agrotins nos revelam a busca de estabelecer uma densidade técnica, científica e informacional para as práticas do agronegócio nessa porção do MATOPIBA. Por conseguinte, apreendemos o alto grau de exterioridade dessa porção do território brasileiro, pois quanto mais tecnicamente for a atividade agrícola maior será a tendência de produzir cultivos com destino ao mercado externo.

Alguns das instituições de ensino e pesquisa agrícola supracitadas foram responsáveis pela oferta de palestras, colóquios, minicursos teóricos e práticos (dia de campo) para o aperfeiçoamento de profissionais e pesquisadores do ramo, e especialmente para os produtores agrícolas. Essas instituições, assim como outros agentes do setor privado, divulgaram novas variedades de sementes híbridas de soja, milho e sorgo, apresentaram uma estação meteorológica automática portátil para monitorar em tempo real a condição atmosférica, demonstraram uma pequena fábrica para a produção de biodiesel, exibiram um sistema de irrigação movido por energia solar (AGROTINS, 2016). 
Além do crescimento do fluxo comercial e financeiro realizado na Agrotins, observamos o aumento da participação do público na feira. Em 2001, o fluxo de pessoas que participaram da Agrotins chegou a 10 mil, já em 2016 quase 86 mil pessoas de diferentes lugares do país foram à feira. Em 2016, a Secretaria do Desenvolvimento da Agricultura e Pecuária do Tocantins (Seagro) organizou caravanas com o objetivo de viabilizar o transporte de membros de associações, cooperativas e comunidades agrícolas de diferentes municípios do estado: Araguatins, Talismã, Natividade, Guaraí, Barrolândia. No total, foram 77 caravanas, o que possibilitou a participação de quase três mil pequenos produtores na Agrotins; ainda cabe mencionar a participação de quase 600 alunos do ensino básico da rede pública (AGROTINS, 2016). Tais informações demonstram que os fluxos de pessoas aumentam no período de realização da Agrotins, e esse é um dos resultados do crescimento dessa feira no cenário regional, produzindo diversos tipos de fluxos por meio do aumento da participação do público, do volume de comércio, do financiamento agrícola, de expositores, e assim por diante.

Segundo relatório da Agrotins (2016), em 2001 houve 88 expositores, dentre eles estão instituições públicas, universidades e órgãos de pesquisa agrícola, cooperativas, sindicatos, bancos, e agentes de comercialização de máquinas e insumos agrícolas; essa quantidade saltou para 630 expositores em 2016, sendo o ano de maior quantidade de expositores desde a primeira edição. Cabe mencionar que quase 140 municípios participaram da edição do ano de 2016 (AGROTINS, 2016). Estiveram presentes, na edição de 2016, uma diversidade de empresas de todo tipo e tamanho, desde firmas locais à multinacionais que atuam em vários setores do agronegócio. A presença dessas empresas demonstra a importância da Agrotins no MATOPIBA. Destacamos a participação da Bunge, Dow Agrosciences e Syngenta, que são grandes empresas voltadas para a venda de sementes e agrotóxico, e das maiores representantes de venda de máquinas e equipamentos como a John Deere, New Holland, Valtra, Agrale etc.

Empresas não relacionadas diretamente com o agronegócio estavam presentes na Agrotins de 2016, tais como a Valor Logística Integrada (VLI) e Empresa Maranhense de Administração Portuária (EMAP), ambas possuem atividades no setor de logística. Recentemente, a VLI começou a operacionalizar a circulação de grãos produzidos em porções do MATOPIBA, a partir da administração da Ferrovia Norte-Sul no trecho entre Açailândia (MA) e Porto Nacional (TO), que soma $720 \mathrm{~km}$ de extensão (VLI, 2017). A EMAP é responsável pela administração do Porto de Itaqui, em São Luís, local onde é embarcada para o mercado externo grande quantidade da soja produzida no MATOPIBA. A VLI e EMAP são agentes importantes dentro do circuito espacial produtivo (SANTOS; SILVEIRA, 2011) do agronegócio no MATOPIBA, pois grande parte da circulação dos grãos produzidos para exportação passam pelos objetos geográficos controlados por essas empresas, sinalizando a importância da logística para o agronegócio no atual período (CASTILLO, 2011).

Sem dúvida, é na Bahia Farm Show, realizada em Luís Eduardo Magalhães (BA), que visualizamos de forma mais expressiva o exibicionismo tecnológico voltado para o campo moderno, pois nesse evento realiza-se o espetáculo mercadológico mais dinâmico 
de todo MATOPIBA, sinalizando o alto grau de especialização regional produtiva dessa porção do território, sobretudo no que diz respeito aos cultivos de soja e algodão. Um dos motivos pelo despontamento dessa feira no contexto regional, quiçá em âmbito nacional, deve-se pela articulação política e econômica da Associação dos Produtores Irrigantes da Bahia (Aiba) e Associação Baiana dos Produtores de Algodão (Abapa), entidades de classe responsáveis pela organização da Bahia Farm Show.

Criada em 1990, a Aiba representa atualmente cerca de 1.300 produtores dessa região que juntos possuem quase 2,25 milhões de hectares de terras plantadas (AIBA, 2017), demonstrando a força de representatividade dessa instituição. Conforme Ilario (2011), a Aiba estabelece diversas parcerias com o setor público e privado para atender as demandas do setor agrícola, sobretudo aos seus associados, em especial no que confere a melhor infraestrutura logística e ações políticas que tornem a atividade mais competitiva. Além disso, a Aiba presta serviços de ordem

[...] administrativa até a jurídica; eventos de capacitação e projeção; base de dados e diversos meios de informação e de comunicação; apoio na elaboração de projetos e análises, assim como em outros aspectos nos campos jurídico, logístico e ambiental. (SANTOS, 2016, p. 221).

Segundo Santos (2016), a Abapa foi fundada em 2000 tendo como missão abrir novas áreas do cerrado baiano para o cultivo de algodão cujo destino é o mercado externo. Assim, busca-se uma estratégia de estabelecer políticas de apoio à comercialização e financiamento agrícola para conseguir atingir um grau de excelência na produção do algodão, bem como na expansão de seu cultivo na região. Ainda de acordo com a referida autora, essa associação possui laboratórios de qualificação de fibras, também desenvolve estudos sobre controle de pragas, além de promover formação técnica de profissionais na área de operação de máquinas agrícolas. Atualmente a Abapa conta com 242 associados espalhados em mais de 300 fazendas do oeste e sudoeste baiano (SANTOS, 2016).

A Aiba e Abapa configuram-se como importantes agentes promotores, juntamente com o Estado e as grandes corporações (tradings agrícolas), de uma "solidariedade organizacional" no espaço agrícola e regional no Oeste baiano, produzindo "[...] normas presididas por interesses de modo geral mercantis, em função de fatores do mercado" (SANTOS; SILVEIRA, 2011, p. 276), sendo responsáveis pela criação de instituições de pesquisa para o desenvolvimento de culturas agrícolas mais competitivas. Uma dessas instituições de pesquisa, resultante da articulação da Aiba e Abapa, é a Fundação de Apoio à Pesquisa e Desenvolvimento do Oeste Baiano (Fundação BA) criada em 1997 a partir da articulação de 29 sócios mantenedores e do Fundo para o Desenvolvimento do Agronegócio do Algodão (FUNDEAGRO) (SANTOS, 2016). Segundo Santos (2016), Aiba e a Abapa, juntamente com a FUNDEAGRO, foram responsáveis pelo surgimento do Centro de Pesquisa e Tecnologia do Oeste da Bahia (CPTO). Desse modo, a Aiba e a Abapa configuram-se como instituições fundamentais 
para a estruturação técnica, produtiva e política do agronegócio na região, sendo a Bahia Farm Show um dos grandes feitos realizados por tais associações.

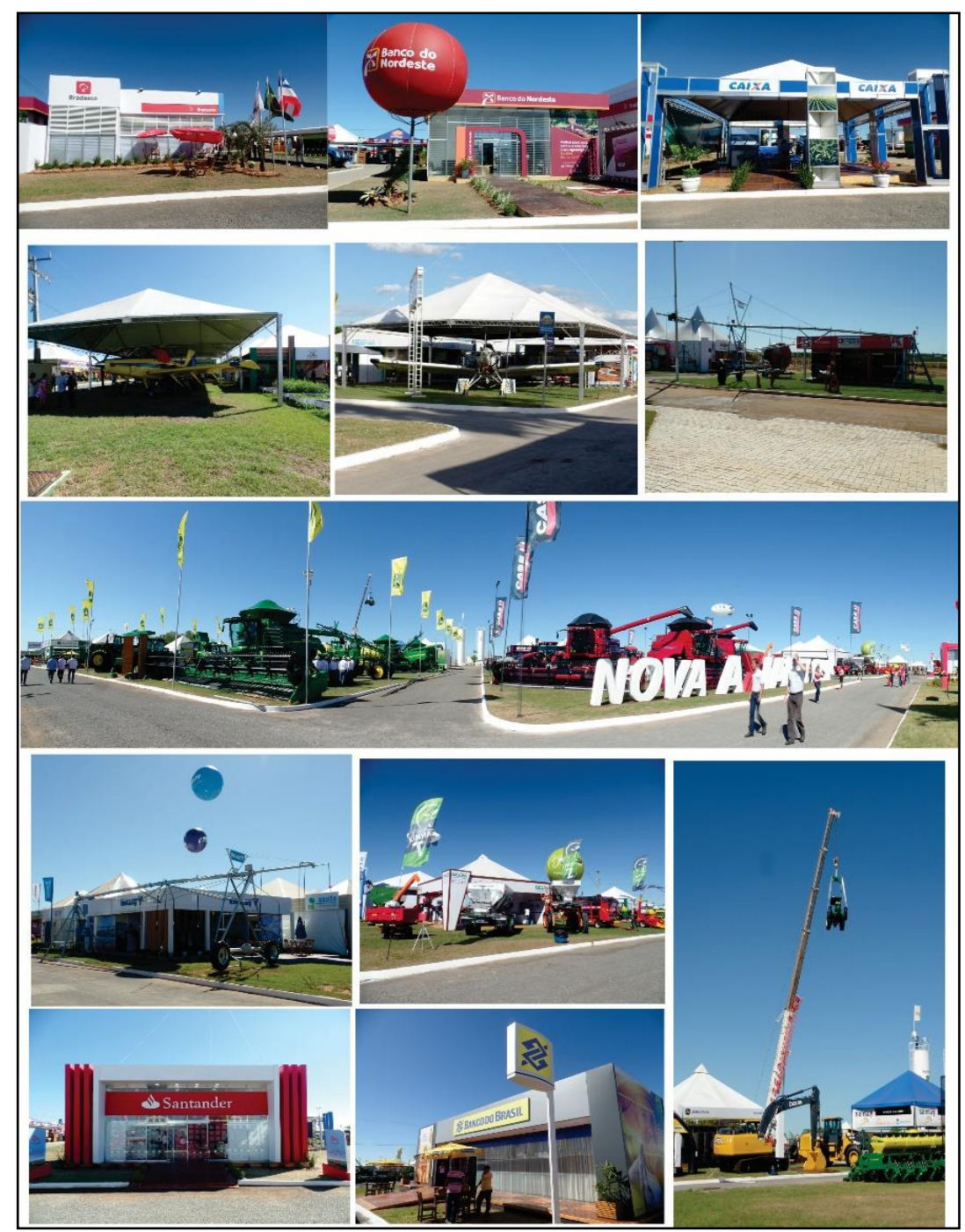

Figura 3. Conjunto de empresas presentes na Bahia Farm Show (2016).

Fonte: Trabalho de campo. Elaborado pelo autor (2016).

Em 2004 foi realizada a primeira edição da Bahia Farm Show, chegando a sua $12^{\mathrm{a}}$ edição em 2016. Desde o início, o evento é realizado em um parque de exposições 
privado (complexo Bahia Farm Show) de 200 hectares, contendo em suas dependências o CPTO e a Fundação BA (BAHIA FARM SHOW, 2017). O CPTO tem uma área construída de $2.302 \mathrm{~m}^{2}$, contando com cinco laboratórios, auditórios para reunião e palestras, dormitórios e refeitório. Além disso, no complexo da Bahia Farm Show há campos experimentais utilizados pela Fundação BA e CPTO, bem como para exposição de cultivos durante a feira; esses campos possuem modernos sistemas técnicos de irrigação por pivô central (cinco pivôs), armazéns e galpões (FUNDAÇÃO BA, 2017).

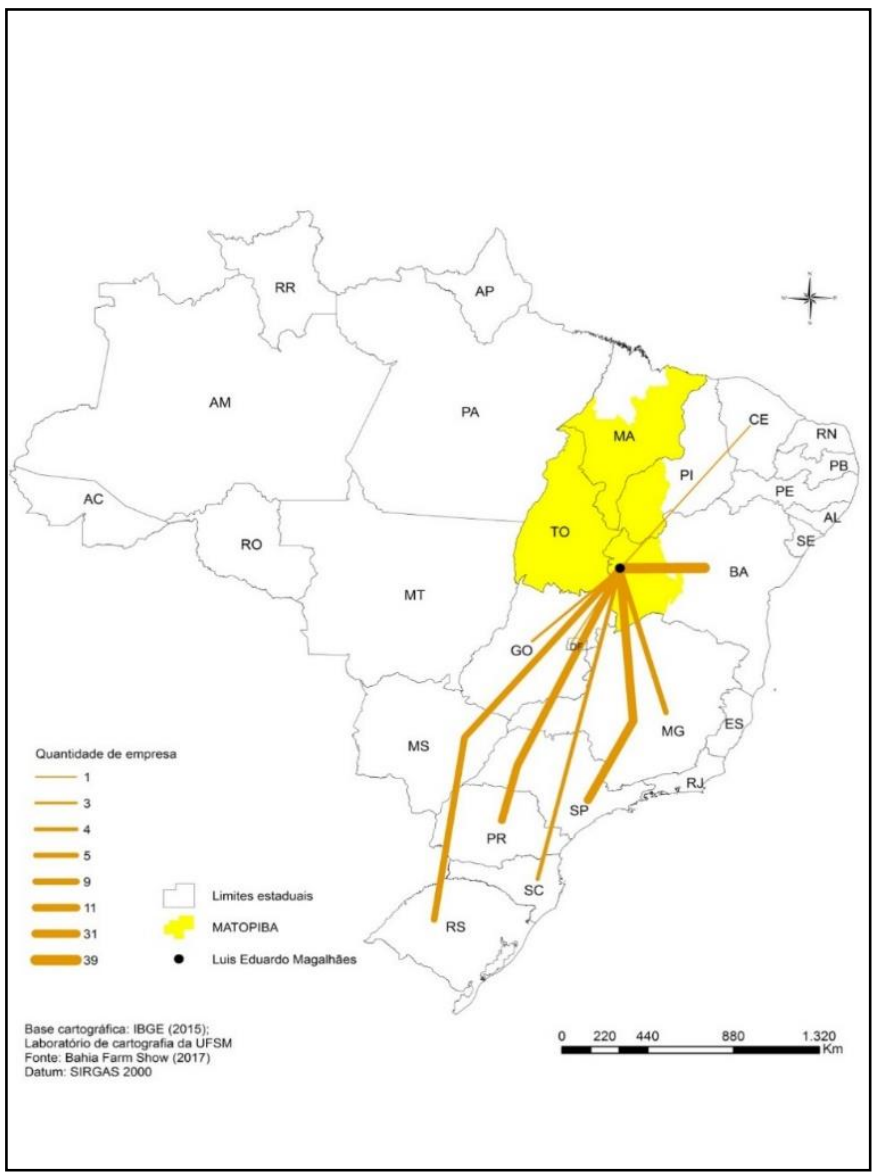

Figura 4. Origem de alguns expositores (por estados) presentes na Bahia Farm Show (2016).

Fonte: Bahia Farma Show (2017). Elaborado pelo autor (2017). 
A $12^{\mathrm{a}}$ edição da Bahia Farm Show contou com a participação dos principais fomentadores do agronegócio, o Estado (prefeitura de Luís Eduardo Magalhães), produtores, organizações civis do agronegócio (Aiba e Abapa), e agentes financeiros (bancos públicos e privados). Segundo informações da Bahia Farm Show (2017), em 2016 a feira contou com cerca de 200 expositores, havia empresas que comercializaram aviões para disseminação de venenos, grandes máquinas e implementos agrícolas, sistemas de irrigação por pivô central, bancos e agentes financeiros, entre outros (Figura 3).

Os organizadores da feira disponibilizaram informações da origem de 104 expositores (mais da metade dos expositores), e dessa quantidade, um número significativo de expositores são oriundos de diferentes regiões do país (Figura 4), principalmente da região concentrada (SANTOS; SILVEIRA, 2011), compreendida pelas macrorregiões Sul e Sudeste na atual proposta de regionalização brasileira do Instituto Brasileiro Geografia e Estatística (IBGE). Das 104 empresas cerca de 58\% vieram dos três estados do Sul e dois estados do Sudeste (Minas Gerais e São Paulo), com destaque a São Paulo, de onde partiram 31 empresas para expor seus produtos na Bahia Farm Show.

Entre as empresas podemos destacar as que comercializam sistema de irrigação como a Bauer, Irrigação Penápolis, Krebs Sistema de Irrigação, Netafim Brasil, Valmont e Lindsay, que são, respectivamente, de São João da Boa Vista (SP), Penápolis (SP), Valinhos (SP), Ribeirão Preto (SP), Uberaba (MG) e Mogi Mirim (SP); a Thrush do Brasil, que vende aeronaves para disseminação de agrotóxicos, é de Anápolis (GO) e a Aeroglobo de Botucatu (SP); montagem de silos para armazenamento de grãos como a Casp de Amparo (SP), a Widitec de Panambi (RS), entre outras empresas que prestam esse tipo de serviço; implementos agrícolas como a Metisa de Timbó (SC), a Trevisan de Palotina (PR), a Tatu Marchesan e Civemasa, ambas de Matão (SP), entre várias outras conforme a Figura 4 (BAHIA FARM SHOW, 2017). Ainda salientamos empresas cujas procedências são de cidades nas quais são produzidas tecnologias para o campo, como Cascavel (PR), Ponta Grossa (PR), São Paulo (SP), Goiânia (GO), Brasília (DF), Porto Alegre (RS) e Santa Maria (RS) (BAHIA FARM SHOW, 2017).

Tal situação, da presença de expositores de vários estados do país, nos indica que alguns produtos demandados pelo agronegócio (em especial maquinário, agroquímicos e sistema de irrigação) comercializados na Bahia Farm Show são provenientes das regiões em que a agricultura moderna é mais antiga. Nesse sentido, percebemos uma cooperação entre os lugares para a realização da Bahia Farm Show, que cria uma "rede" de solidariedade para atender as necessidades de consumo produtivo do campo moderno no MATOPIBA de forma geral, e em específico no Oeste baiano.

Essa "rede" de solidariedade estrutura uma hierarquização do território para as demandas do agronegócio no MATOPIBA, pois lugares distantes à essa região são responsáveis por produzir os objetos técnicos para a realização do agronegócio nessa porção do território, ou seja, essa trama de relações para a disseminação do consumo produtivo realizado na Bahia Farm Show é marcada por um acontecer hierárquico (SANTOS, 2002). De acordo com Santos (2002), o acontecer hierárquico é atributo de 
relações pontuais no território, em que ordens e informações (informações presentes nos objetos) geradas em um determinado lugar se efetivam em outros lugares (distantes ou próximos), é "[...] um dos resultados da tendência à racionalização das atividades e se faz sob um comando, uma organização, que tendem a ser concentrados" (SANTOS, 2002, p. 167).

Apesar da grande presença de expositores da região concentrada, ao menos 39 expositores (dentre os 104 avaliados) têm como origem o estado da Bahia; a maior parte deles são do Oeste baiano como São Desidério (duas empresas), Barreiras (cinco empresas) e Luís Eduardo Magalhães (24 expositores), sinalizando o nível de especialização do terciário (comércio e serviço) dessas cidades para o consumo produtivo do campo moderno. Sem dúvida as empresas que mais ocupam espaço durante a Bahia Farm Show são oriundas de Luís Eduardo Magalhães, como as vendedoras de máquinas agrícolas AgroSul (representante da John Deere), Maxum (revendedora da Case) e Jaraguá Bahia (concessionária da New Holland). Além desses municípios baianos, houve a presença de outras empresas do estado da Bahia, sobretudo daquelas relacionadas ao setor petroquímico de Salvador e Camaçari, assim como expositores de Lauro de Freitas (BAHIA FARM SHOW, 2017).

Todo esse conjunto de informações nos sinaliza a capacidade que essa feira do agronegócio tem em produzir fluxos de diversos tipos de empresas de várias porções do território brasileiro, demonstrando que as empresas expositoras nesse evento são nutridas por expectativas de realizarem grandes negócios, justificando o deslocamento para Luís Eduardo Magalhães.

Um dado que nos revela o crescimento da Bahia Farm Show nesses últimos anos é o aumento do volume de negociações. Conforme Alves (2005), em 2005 houve a movimentação de $\mathrm{R} \$ 220$ milhões na comercialização de produtos e oferta de serviços na referida feira, e essa quantidade superou R \$ 1 bilhão em 2016 (BAHIA FARM SHOW, 2017). Os setores que mais se destacaram nas negociações da edição de 2016 foram o de irrigação, automóveis, fertilizantes, sementes e agropecuária. Todo esse crescimento econômico vem atraindo a participação de mais pessoas - em 2016 cerca de 60 mil visitantes foram ao complexo da Bahia Farm Show, entre expositores, pesquisadores, produtores rurais, e o público em geral.

Salientando, novamente, a presença dos órgãos de financiamento que criam linhas de crédito diferenciadas para os agricultores, ao total a feira teve seis instituições. Conforme informações da Agronews Oeste (2016), o Banco do Brasil disponibilizou três linhas de crédito: Programa Nacional de Apoio ao Médio Produtor Rural (Pronamp), voltado para o custeio e despesas da produção, tendo prazo de dois anos para quitar a dívida, com taxas de juros a partir de 7\% ao ano; o Pronamp Investimentos que é destinado para aquisição de bens e frota - esse tipo de financiamento cobra juros a partir de 7,5\% ao ano, com período de oito anos para pagar o empréstimo; por fim, o Programa para Construção e Ampliação de Armazéns (PCA) disponibilizou ao produtor crédito que pode ser pago em até 15 anos, a juros a partir de 7,5\% ao ano. 
Ainda segundo Agronews Oeste (2016), a Caixa Econômica Federal ofertou linhas de créditos especiais, disponibilizando um volume de $\mathrm{R} \$ 385$ milhões a serem concedidos na Bahia Farm Show de 2016, com taxas de juros de 8,75\% ao ano; o Banco Santander ofereceu isenção da taxa flat fee, que é uma cobrança de $1 \%$ a $3 \%$ do valor total da compra. Além disso, caso o produtor consiga dar uma entrada de ao menos $20 \%$ do valor do produto, a própria mercadoria garante a operação. A partir de repasses do Banco Nacional de Desenvolvimento Social (BNDS) o Banco Bradesco concedeu crédito a partir de três linhas: o Moderfrota para aquisição de máquinas agrícolas, o PCA para armazéns e silos, e o Moderinfra voltado para a modernização de infraestrutura; a feira ainda contou com a participação do Banco do Nordeste e da Agência de Fomento do Estado da Bahia (Desenbahia). Tais medidas tornam o acesso ao crédito agropecuário mais fácil, viabilizando e incentivando a aquisição de produtos e serviços especializados ao agronegócio, e assim os financiamentos facilitados por essas instituições fomentam as trocas de mercadoria e dinheiro na região.

Para além da importância econômica e da difusão de tecnologia, a Bahia Farm Show tem o papel de instruir os produtores por meio de palestras, colóquios e mesas de discussão em que são debatidos assuntos diversos como: melhores práticas agrícolas, gestão financeira, regularização fundiária, sustentabilidade e política ambiental, agricultura de precisão, gestão de risco e mercado do agronegócio. Esse conjunto de palestras visa a instrução técnica, financeira e jurídica dos produtores, para que possam estabelecer estratégias para o fortalecimento do agronegócio na região, sendo realizadas 29 palestras em 2016 (BAHIA FARM SHOW, 2017).

Merece ser destacado o fórum de discussão "MATOPIBA: potencialidades e desafios", pois o mesmo contou com a participação dos presidentes da Aiba e Abapa, representantes do poder executivo do estado da Bahia e do Piauí, membros do Ministério da Agricultura Pecuária e Abastecimento (MAPA), além do coordenador do grupo vinculado à Embrapa (GITE). Nessa roda de discussão foram debatidos assuntos como os problemas de logística, em especial a inconclusão da ferrovia Oeste-leste que conectaria o oeste baiano ao litoral da Bahia, e as dificuldades que os produtores estão tendo para pagar os financiamentos junto aos bancos e tradings agrícolas. Além disso, foram discutidas as áreas do MATOPIBA ainda não ocupadas pela atividade agrícola moderna, configurando-se como áreas de reservas para a expansão do agronegócio; as expectativas de fortalecimento da atividade agrícola a partir da difusão de novas tecnologias; e o quanto a região está obtendo saldos positivos na sua produção e produtividade.

Dessa maneira, reconhecemos que essa feira do agronegócio se configura como um notável espaço da articulação política, no qual são desenhadas, por diversos agentes do agronegócio, estratégias para o aprofundamento dessa prática econômica e política no MATOPIBA. Além do mais, proporciona uma prática agrícola cada vez mais carregada de conteúdo técnico, científico e informacional, através do adensamento do uso de objetos modernos. 


\section{Considerações finais}

Como pudemos verificar, as feiras do agronegócio, sobretudo as maiores, são resultantes do próprio processo de verticalização da especialização territorial produtiva reconhecida no MATOPIBA, a partir dos anos 2000, e tal crescimento na produção de commodities vem demandando o consumo de produtos sem os quais a produção agrícola não se realizaria. Nesse sentido, as feiras do agronegócio configuram-se como espaços que concentram diversas empresas especializadas para a difusão de objetos carregados de conteúdos informacional e científico inerentes ao agronegócio. Isso posto, pode-se apreender que esses eventos que comercializam produtos essenciais para agricultura moderna derivam da própria necessidade de consumo produtivo promovido pela modernização das práticas produtivas no campo no MATOPIBA.

A realização das feiras do agronegócio está colaborando para a produção de uma nova geografia no MATOPIBA, pois em um curto período de tempo, normalmente uma semana, elas conseguem injetar milhões, e até mesmo bilhões de reais na economia urbana das cidades que realizam esse tipo de evento agrícola. Certamente a Agrotins, e fundamentalmente a Bahia Farm Show são as maiores feiras do agronegócio na região, sendo responsáveis pela comercialização e difusão de novas variedades de tecnologia para tornar a atividade agrícola mais integrada com a economia internacional, pois grande parte dos produtos expostos são voltados para os maiores produtores que possuem interesse de cultivar commodities mais valorizadas para a exportação. Diversos tipos de público (empresários, expositores, produtores, estudantes, políticos etc.) oriundos de diversas partes do Brasil participam das feiras do agronegócio, demonstrando o poder que elas possuem para atrair e dimensionar fluxos de vários tipos e intensidades, animando a vida política, econômica e social do MATOPIBA.

Indubitavelmente, as feiras do agronegócio colaboram para o adensamento técnico para a agricultura moderna no MATOPIBA. Esse adensamento de objetos técnicocientíficos em partes é viabilizado pelas ações do Estado através de políticas públicas, pela oferta de crédito agrícola e pelo investimento em pesquisa para o desenvolvimento de cultivos mais competitivos. Além de propiciar a condição material para o agronegócio, o Estado (representado pela elite dirigente local) acaba fomentando uma psicosfera modernizadora, incentivando o consumo de modernos objetos técnicos. Dessa forma, as feiras do agronegócio também são eventos de cunho político nos quais são disseminados os discursos e as ideologias dos atores hegemônicos do setor. Assim, observamos nessas feiras as articulações do Estado e do setor privado para tornar essa porção do território cada vez mais racionalizada aos imperativos do agronegócio globalizado, a partir da constituição de uma tecnosfera e uma psicosfera modernizadora. 


\section{Referências}

AGROBALSAS. Informações sobre a feira. 2016. Disponível em: < http://agrobalsas.fapcen.agr.br/>. Acesso em: 7 mar. 2017.

AGRONEWS OESTE (Ed.). Feira se adéqua à crise. Agronews Oeste, [s.1], v. 12, n. 42, p.18-26, maio 2016.

AGROTINS. Relatório Agrotins 2001. [s.1]: Governo do Tocantins, 2001.

AGROTINS. Relatório Agrotins 2016. [s.1]: Governo do Tocantins, 2016.

AIBA. Associação dos Produtores Irrigantes da Bahia. Institucional. 2017. Disponível em: <http://aiba.org.br/>. Acesso em: 10 fev. 2017.

ALVES, V. E. L. Barreiras/ Luís Eduardo Magalhães (BA), Balsas (MA), Uruçuí/ Bom Jesus (PI): as novas cidades para o agronegócio nos cerrados nordestinos. In: SIMPÓSIO NACIONAL DE GEOGRAFIA AGRÁRIA, 3.; SIMPÓSIO INTERNACIONAL DE GEOGRAFIA AGRÁRIA JORNADA ARIOVALDO UMBELINO DE OLIVEIRA, 2, 2005, Presidente Prudente. Anais... Presidente Prudente: Unesp, 2005. [s.p].

BAHIA FARM SHOW. Informações sobre a feira. 2017. Disponível em: < http://bahiafarmshow.com.br/>. Acesso em: 8 mar. 2017.

BERNARDES, J. A. Fronteiras da agricultura moderna no cerrado Norte/Nordeste: descontinuidades e permanências". In: BERNARDES, J. A.; BRANDÃO F. J. B. (Org.). Geografias da soja II: a territorialidade do capital. Rio de Janeiro: Arquimedes/CNPq, 2009. p. 13-40.

BRASIL. Decreto $\mathrm{n}^{\circ}$ 8.447, de 6 de maio de 2015. Plano de Desenvolvimento Agropecuário do Matopiba e a Criação de Seu Comitê Gestor. Brasília, 6 de maio de 2015.

CASTILLO, R. Agricultura globalizada e logística nos cerrados brasileiros. In: SILVEIRA, M. R. (Org.). Circulação, transportes e logística diferentes perspectivas. São Paulo: Outras expressões, 2011. p. 331-354.

COSTA, L. Dias entrega títulos de terra durante a Feira Piauí Agroshow. Portal do Governo do estado do Piauí. 2016. Disponível em:

$<$ http://www.piaui.pi.gov.br/noticias>. Acesso em: 16 fev. 2017.

ELIAS, D. Trabalho de campo: notas teórico-metodológicas. Geousp, São Paulo, v.1, n. 5, p. 97-108, 1999.

ELIAS, D. Globalização e agricultura: a região de Ribeirão Preto - SP. São Paulo: Edusp, 2003.

ELIAS, D. Globalização e fragmentação do espaço agrícola no Brasil. Scripta Nova, Barcelona, v. 1, n. 2, p. 51-68, 2006. 
FAEB. Federação da Agricultura e Pecuária do Estado da Bahia; SENAR - Serviço Nacional de Aprendizagem Rural. Relatório de atividades 2015. [s.1]: FAEB/SENAR, 2015.

FAEMA. Federação da Agricultura e Pecuária do Estado do Maranhão; SENAR Serviço Nacional de Aprendizagem Rural. Calendário de exposições, leiloes e feiras agropecuárias do Maranhão. 2015. Disponível em: <http://senarma.org.br/cronograma-de-eventos/>. Acesso em: 14 fev. 2017.

FAET. Federação da Agricultura e Pecuária do Estado do Tocantins. Calendário de eventos agropecuários do estado do Tocantins 2016. 2016. Disponível em: $<$ http://www.faetrural.com.br/>. Acesso em: 13 fev. 2017.

FUNDAÇÃO BA. Fundação de Apoio à Pesquisa e Desenvolvimento do Oeste Baiano. A Fundação. Disponível em: <http://www.fundacaoba.com.br/index.php?p=afundacao $>$. Acesso em: 13 mar. 2017.

FUNDAÇÃO BA. $6^{a}$ Piauí Exposhow acontece em Bom Jesus com muitas oportunidades de negócios. 2014. Disponível em: <http://g1.globo.com/pi/piaui/cluberural/videos/v/6a-piaui-exposhow-acontece-em-bom-jesus-com-muitas-oportunidadesde-negocios/3401550/>. Acesso em: 07 mar. 2017.

FUNDAÇÃO BA. Empreendimentos agrícolas abrem caminhos para os pequenos negócios. 2015. Disponível em:

$<$ http://g1.globo.com/ma/maranhao/noticia/2015/04/empreendimentos-agricolas-abremcaminhos-para-os-pequenos-negocios.html>. Acesso em: 13 fev. 2017.

GITE. Grupo de Inteligência Territorial Estratégica. Proposta de delimitação territorial do MATOPIBA. Campinas: Embrapa, 2014. Disponível em:

$<$ https://www.embrapa.br/gite >. Acesso: em 19 out. 2015.

FUNDAÇÃO BA. Renda e pobreza rural na região do MATOPIBA. Campinas:

Embrapa, 2015. Disponível em: <https://www.embrapa.br/gite>. Acesso em: 25 ago. 2016.

IBGE. Instituto Brasileiro de Geografia e Estatística/ PAM - Produção Agrícola Municipal. Sistema IBGE de recuperação automática (SIDRA). 2017. Disponível em: $<$ http://www2.sidra.ibge.gov.br>. Acesso em: 4 fev. 2017.

INOCÊNCIO, M. E. O Prodecer e as tramas da territorialização do capital no Cerrado. 2010. 271 f. Tese (Doutorado) - Programa de Pós-Graduação/ IESA, Universidade Federal do Goiás, Goiânia, 2010.

ILARIO, C. G. Região agrícola competitiva e logística no oeste baiano. 2011. 142 f. Dissertação (Mestrado) - Geografia, Universidade Estadual de Campinas, Campinas, 2011. 
PEIXINHO, D. M.; SCOPEL, I. A territorialização da agricultura moderna no Piauí. In: BERNARDES, J. A.; BRANDÃO FILHO, J. B. (Org.). Geografias da soja II: a territorialidade do capital. Rio de Janeiro: Arquimedes/CNPq, 2009. p. 13-40.

PEREIRA, M. F. V. Difusão da inovação, consumo e cotidiano no campo moderno: notas sobre o papel das feiras agropecuárias em Rondônia (Brasil). Raega, v. 21, n. 1, p.04-19, 2011.

RIBEIRO, A. C. T. O poder (des)organizador dos meios de comunicação. In: PIQUET, R.; RIBEIRO, A. C. T. (Org.). Brasil território da desigualdade: descaminhos da modernização. Rio de Janeiro: Jorge Zahar, 1991. p. 44-55.

SANTOS, C. D. Difusão do agronegócio e reestruturação urbano-regional no Oeste baiano. 2016. 450 f. Tese (Doutorado) - Geografia, Universidade Estadual do Ceará, Fortaleza, 2016.

SANTOS, M. et al. O papel ativo da Geografia: um manifesto. In: ENCONTRO NACIONAL DE GEÓGRAFOS, 12., 2010, Florianópolis. Anais... Florianópolis, 2000. p. 103-109.

SANTOS, M. Por uma outra globalização: do pensamento único à consciência universal. Rio de Janeiro: Record, 2001.

SANTOS, M. A natureza do espaço: técnica e tempo; razão e emoção. São Paulo: Edusp, 2002.

SANTOS, M. A urbanização brasileira. São Paulo: Edusp, 2009.

SANTOS, M.; SILVEIRA, M. L. S. O Brasil: território e sociedade no início do século XXI. Rio de Janeiro: Best Bolso, 2011.

SDR. Secretária de Desenvolvimento do Piauí. Divulgado o calendário de eventos agropecuários da SDR em 2013. 2013. Disponível em:

<http://www.piaui.pi.gov.br/noticias>. Acesso em: 13 fev. 2017.

TEIXEIRA, E. Exposhow reúne 180 fabricantes de máquinas agrícolas. G1, Piauí, 12 jun. 2013. Disponível em: <http://g1.globo.com/pi/piaui/noticia/2013/06/piauiexposhow-reune-180-fabricantes-de-maquinas-agricolas.html>. Acesso em: 18 fev. 2017

TELES, M. Piauí AgroShow movimenta mais de R\$ 200 milhões em Bom Jesus. Portal do Governo do estado do Piauí. 2014. Disponível em:

$<$ http://www.piaui.pi.gov.br/noticias>. Acesso em: 15 fev. 2017.

VENCOVSKY, V. P. Ferrovia e logística do agronegócio globalizado: avaliação das políticas públicas e privadas do sistema ferroviário brasileiro. $198 \mathrm{f}$. Tese (Doutorado) Curso de Geografia, Universidade de Campinas, Campinas, 2011.

VLI. Valor Logística Integrada. Ferrovias. Disponível em: $<$ http://www.vlilogistica.com>. Acesso em: 15 fev. 2017. 
YOSHII, K. Programa de Cooperação Nipo-Brasileira para o Desenvolvimento dos Cerrados - Prodecer. In: YOSHII, Kazuiro; CAMARGO, Amambílio J. A. de; ORIOLI, Álvaro Luiz (Org.). Monitoramento ambiental nos projetos agrícolas do PRODECER. Planaltina, DF: CAMPO/EMBRAPA Cerrados/JICA, 2000. p. 27-34.

*Este trabalho resulta de pesquisa de mestrado financiada pelo Fundação de Amparo à Pesquisa do Estado de Minas Gerais (FAPEMIG) entre os anos 2015 e 2017.

Glaycon Vinícios Antunes de Souza

Possui graduação (licenciatura e bacharelado) e mestrado em Geografia pela Universidade Federal de Uberlândia. Atualmente é doutorando em Geografia pela Universidade Estadual de Campinas.

Instituto de Geociências - Programa de Pós-Graduação em Geografia. R. Carlos Gomes, 250 - Cidade Universitária, Campinas, São Paulo. CEP: 13083-855.

E-mail: glayconantunes@hotmail.com

Recebido para publicação em maio de 2017 Aprovado para publicação em agosto de 2018 